10. Wang XZ, Lü CJ, Gao FQ Li XH, Yan WF, Ning FY. Efficacy of goal-directed therapy in the treatment of septic shock [in Chinese]. Zhongguo Wei Zhong Bing Ji Jiu Yi Xue. 2006;18(11):661-664.

\section{Rebuttal From Dr Rivers et al}

\section{An End Point Must Be Consistently Present to Be Generalized}

L evraut et al ${ }^{1}$ stated, "It is common knowledge that many septic patients develop multiple organ failure and die despite normal blood lactate levels." Below the critical systemic oxygen delivery, central venous oxygen saturation $\left(\mathrm{ScvO}_{2}\right)$ decreases; however, lactate level elevation may not occur. More importantly, an $\mathrm{ScvO}_{2} \geq 70 \%$ is not the only goal, as achievement of all early goal-directed therapy (EGDT) goals actually resulted in an $\mathrm{ScvO}_{2} \geq 77.3 \%$. According to Dr Jones, ${ }^{2}$ a study by Gattinoni et $\mathrm{al}^{3}$ did not show an outcome benefit of reaching a mixed venous oxygen saturation of $70 \%$ up to $48 \mathrm{~h}$ after ICU admission. However, Chamberlain et $\mathrm{al}^{4}$ found in a meta-analysis that patients resuscitated to this end point within a more reasonable $6 \mathrm{~h}$ were twice as likely to survive than those without it.

\section{A Repeat Look at a Previously QUOTED STUDY}

Dr Jones ${ }^{2}$ cites the study by Jansen et $\mathrm{al}^{5}$ as supportive of lactate clearance, but not all patients in that study were septic. Furthermore, the reduction of lactate was no faster when the control group therapy was compared with the lactate-guided aggressive resuscitation group. In fact, these authors concluded that "this observation might actually argue against lactate level as a target of hemodynamic therapy. However, given that $\mathrm{ScvO}_{2}$ monitoring was mandatory in the lactate group and control group, we cannot exclude the possibility that this had an impact on the observed outcome difference." 5

\section{Does Noninferiority Mean EQuivalency? Be Careful What You Read}

Noninferiority is a double negative that may confuse clinicians because of the complexity of study design. Noninferiority trials are controversial and difficult to design, conduct, analyze, and interpret for trialists, clinicians, reviewers, and editors. ${ }^{6}$ The low number of interventions observed by Jones et $\mathrm{al}^{7}$ bias toward the conclusion of noninferiority. Thus, for appropriate interpretation, one must be aware of and apply the CONSORT (Consolidated Standards of Reporting Trials) recommendations on noninferiority and equivalence trials (Table 1). ${ }^{6-10}$

\section{Responding to Perceived Barriers}

Barriers specified by Dr Jones ${ }^{2}$ are unacceptable as excuses for our failure to save lives. We do not avoid complex interventions for trauma, stroke, or myocardial infarction. Severe sepsis carries a mortality risk far in excess of these acknowledged emergencies. Surely, placement of central lines, as well as continuous or intermittent venous saturation measurement, should be well within the capabilities of competent emergency and critical care practitioners.

\section{CONCLUSION}

Today's clinical tools for assessing tissue perfusion, including $\mathrm{ScvO}_{2}$ and lactate level, have benefits and limitations. $\mathrm{ScvO}_{2}$ has a half-life of seconds, providing value as an early goal of resuscitation with interpretation potentially confounded by changes in systemic oxygen delivery, tissue extraction, and distribution of blood flow at both the macrocirculatory and microcirculatory levels. Serum lactate levels may remain normal before and throughout resuscitation or fluctuate due to the complexities of lactate kinetics, causing one to question the clinical usefulness of lactate clearance. Moreover, a $10 \%$ drop in serum lactate level has different implications if the initial value is $12 \mathrm{mmol} / \mathrm{L}$ rather than $4 \mathrm{mmol} / \mathrm{L}$. The concept of lactate clearance as the single goal of resuscitation is, therefore, flawed and potentially dangerous. Today's prudent clinician will use both normalization of $\mathrm{ScvO}_{2}$ and lactate levels to guide resuscitation rather than rely on one parameter alone.

\section{Emanuel P. Rivers, MD, MPH, FCCP \\ Detroit, $M I$ \\ Ronald Elkin, $M D$ \\ San Francisco, CA \\ Chad M. Cannon, MD \\ Kansas City, KS}




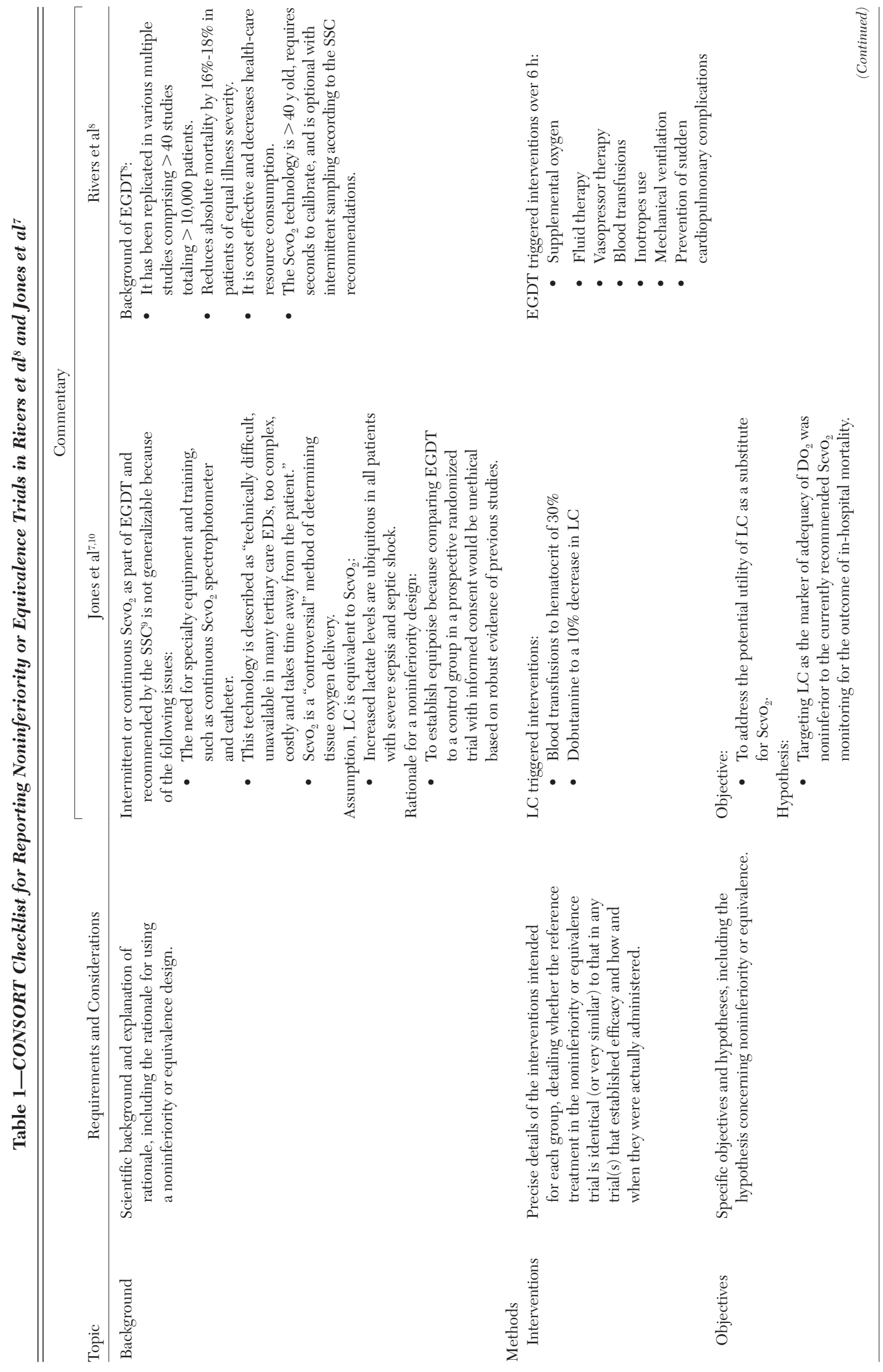



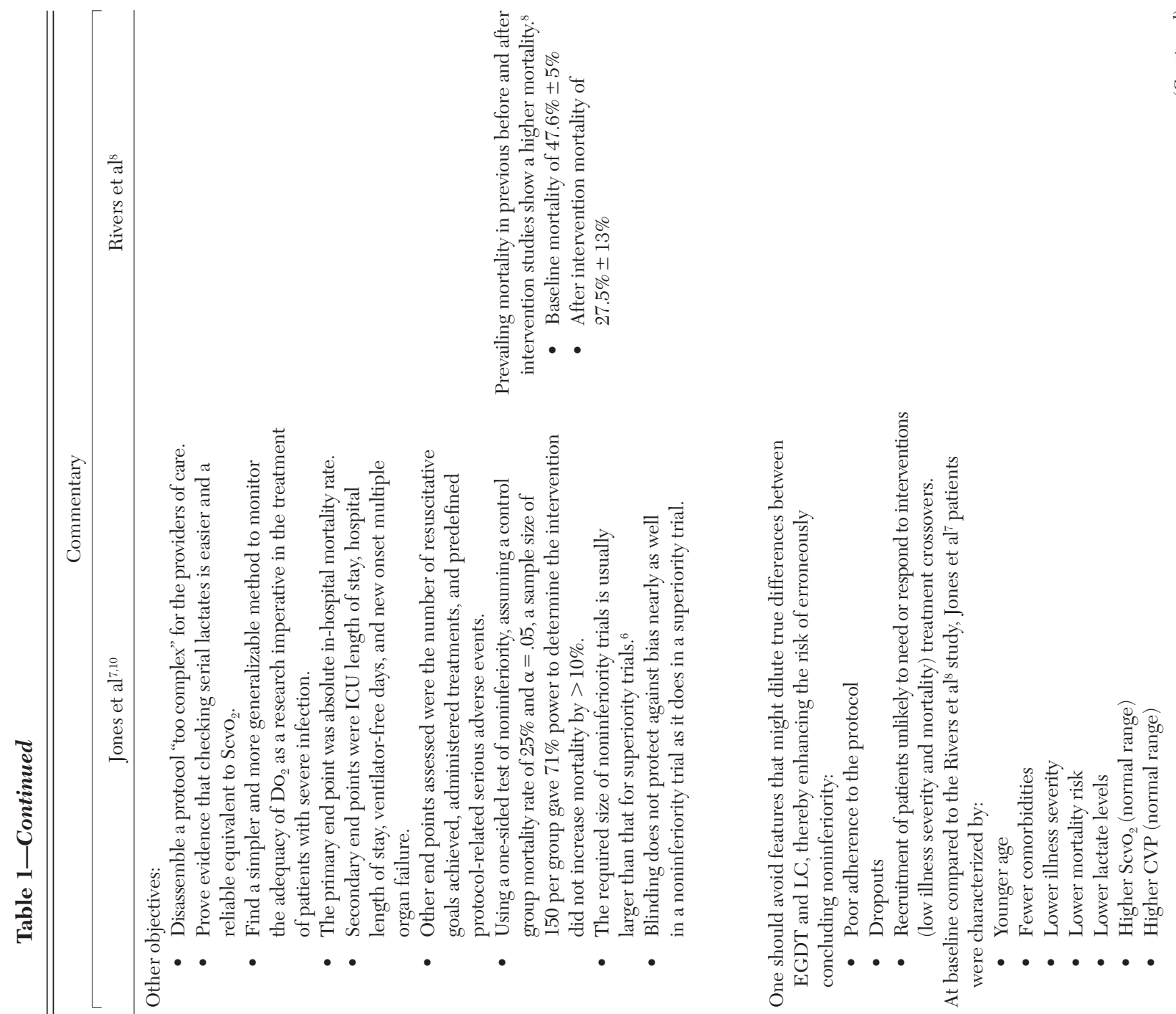

\section{节}

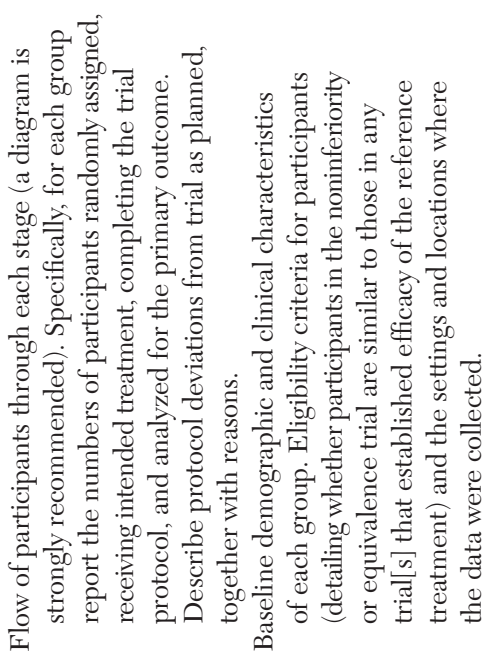

产

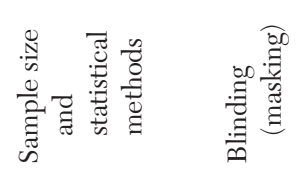

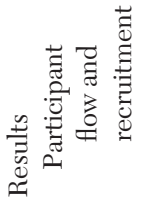

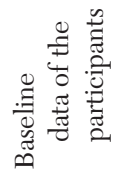




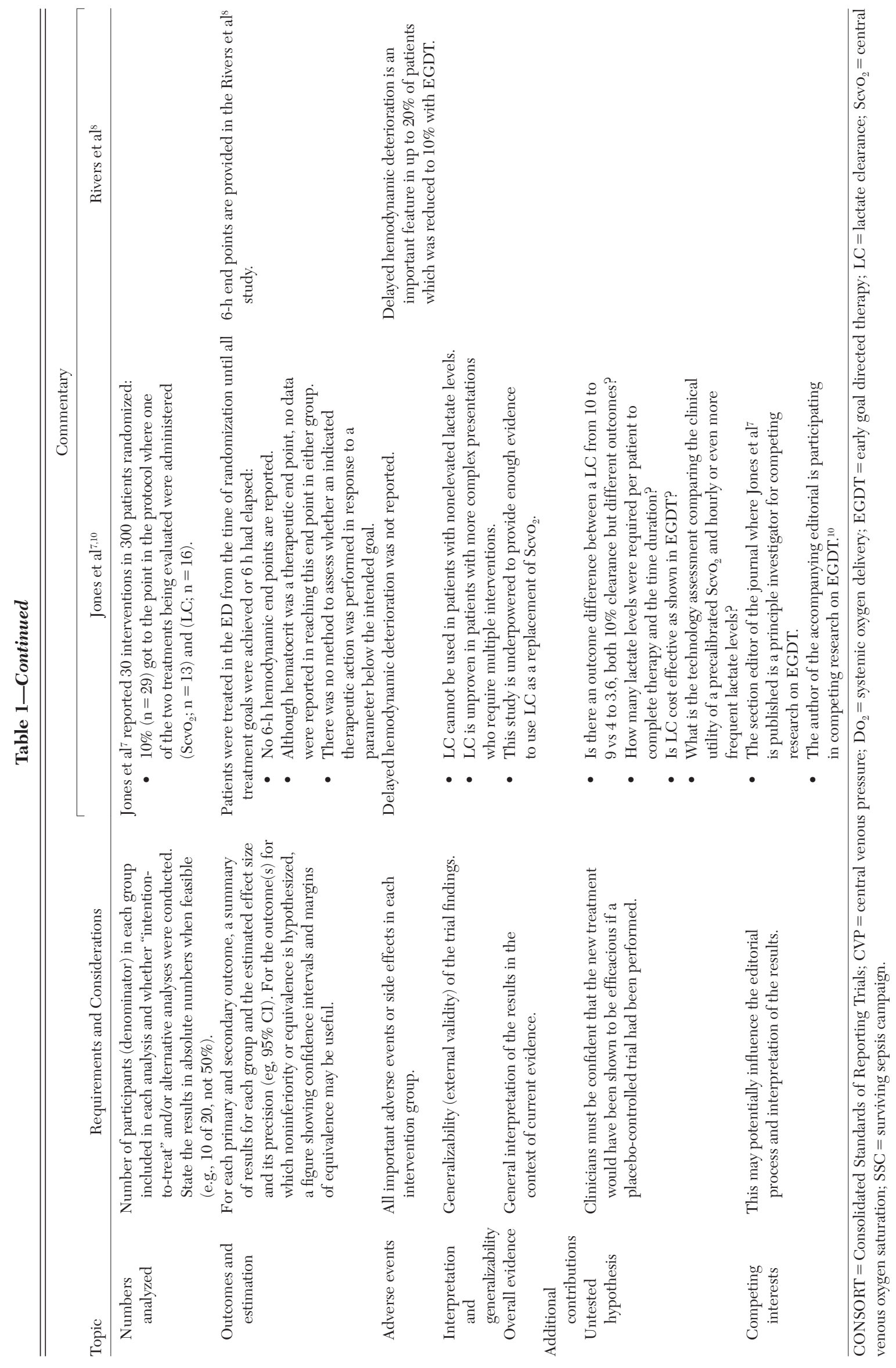


Correspondence to: Emanuel P. Rivers, MD, MPH, FCCP, Department of Emergency Medicine, Wayne State University, 270 Clara Ford Pavilion, Henry Ford Hospital, 2799 W Grand Blvd, Detroit, MI 48202; e-mail: erivers1@hfhs.org

(C) 2011 American College of Chest Physicians. Reproduction of this article is prohibited without written permission from the American College of Chest Physicians (http://www.chestpubs.org/ site/misc/reprints.xhtml)

DOI: 10.1378/chest.11-2599

\section{REFERENCES}

1. Levraut J, Ichai C, Petit I, Ciebiera JP, Perus O, Grimaud D. Low exogenous lactate clearance as an early predictor of mortality in normolactatemic critically ill septic patients. Crit Care Med. 2003;31(3):705-710.

2. Jones AE. Point: should lactate clearance be substituted for central venous oxygen saturation as goals of early severe sepsis and septic shock therapy? Yes. Chest. 2011;140(6): 1406-1408.

3. Gattinoni L, Brazzi L, Pelosi P, et al. A trial of goal-oriented hemodynamic therapy in critically ill patients. SvO2 Collaborative Group. N Engl J Med.1995;333(16):1025-1032.

4. Chamberlain DJ, Willis EM, Bersten AB. The severe sepsis bundles as processes of care: a meta-analysis [published online ahead of print February 14, 2011]. Aust Crit Care.

5. Jansen TC, van Bommel J, Schoonderbeek FJ, et al; LACTATE study group. Early lactate-guided therapy in intensive care unit patients: a multicenter, open-label, randomized controlled trial. Am J Respir Crit Care Med. 2010;182(6):752-761.
6. Piaggio G, Elbourne DR, Altman DG, Pocock SJ, Evans SJ; CONSORT Group. Reporting of noninferiority and equivalence randomized trials: an extension of the CONSORT statement. JAMA. 2006;295(10):1152-1160.

7. Jones AE, Shapiro NI, Trzeciak S, Arnold RC, Claremont HA, Kline JA; Emergency Medicine Shock Research Network (EMShockNet) Investigators. Lactate clearance vs central venous oxygen saturation as goals of early sepsis therapy: a randomized clinical trial. JAMA. 2010;303(8):739-746.

8. Rivers EP. Point: adherence to early goal-directed therapy: does it really matter? Yes. After a decade, the scientific proof speaks for itself. Chest. 2010;138(3):476-480.

9. Dellinger RP, Levy MM, Carlet JM, et al; International Surviving Sepsis Campaign Guidelines Committee; American Association of Critical-Care Nurses; American College of Chest Physicians; American College of Emergency Physicians; Canadian Critical Care Society; European Society of Clinical Microbiology and Infectious Diseases; European Society of Intensive Care Medicine; European Respiratory Society; International Sepsis Forum; Japanese Association for Acute Medicine; Japanese Society of Intensive Care Medicine; Society of Critical Care Medicine; Society of Hospital Medicine; Surgical Infection Society; World Federation of Societies of Intensive and Critical Care Medicine. Surviving Sepsis Campaign: international guidelines for management of severe sepsis and septic shock: 2008. Crit Care Med. 2008;36(1):296-327.

10. Lewis RJ. Disassembling goal-directed therapy for sepsis: a first step. JAMA. 2010;303(8):777-779. 